ORIGINAL ARTICLE

\title{
Trisomic dose of several chromosome 21 genes perturbs haematopoietic stem and progenitor cell differentiation in Down's syndrome
}

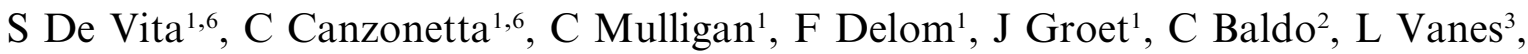 \\ F Dagna-Bricarelli², A Hoischen ${ }^{4}, \mathrm{~J} \mathrm{Veltman}^{4}$, EMC Fisher $^{5}$, VLJ Tybulewicz ${ }^{3}$ and D Nizetic ${ }^{1}$
}

${ }^{1}$ Queen Mary University of London, Blizard Institute of Cell and Molecular Science, Barts and The London School of Medicine and Dentistry, Centre for Paediatrics, London, UK; ${ }^{2}$ Galliera Genetic Bank, Human Genetics Laboratory, Galliera Hospital, Genoa, Italy; ${ }^{3}$ MRC-National Institute for Medical Research, Mill Hill, London, UK; ${ }^{4}$ Department of Human Genetics, Radboud University Nijmegen Medical Centre, Nijmegen, The Netherlands and ${ }^{5}$ Department of Neurodegenerative Disease, UCL-Institute of Neurology, London, UK

Children with Down's syndrome (DS) have 20-50-fold higher incidence of all leukaemias (lymphoid and myeloid), for reasons not understood. As incidence of many solid tumours is much lower in DS, we speculated that disturbed early haematopoietic differentiation could be the cause of increased leukaemia risk. If a common mechanism is behind the risk of both major leukaemia types, it would have to arise before the bifurcation to myeloid and lymphoid lineages. Using the transchromosomic system (mouse embryonic stem cells (ESCs)) bearing an extra human chromosome 21 (HSA21)) we analyzed the early stages of haematopoietic commitment (mesodermal colony formation) in vitro. We observed that trisomy 21 (T21) causes increased production of haemogenic endothelial cells, haematopoietic stem cell precursors and increased colony forming potential, with significantly increased immature progenitors. Transchromosomic colonies showed increased expression of Gata-2, c-Kit and Tie-2. A panel of partial T21 ESCs allowed us to assign these effects to HSA21 subregions, mapped by $3.5 \mathrm{kbp}$-resolution tiling arrays. The Gata-2 increase on one side, and c-Kit and Tie-2 increases on the other, could be attributed to two different, nonoverlapping HSA21 regions. Using human-specific small interfering RNA silencing, we could demonstrate that an extra copy of RUNX1, but not ETS-2 or ERG, causes an increase in Tie-2/c-Kit levels. Finally, we detected significantly increased levels of RUNX1, C-KIT and PU.1 in human foetal livers with T21. We conclude that overdose of more than one $H S A 21$ gene contributes to the disturbance of early haematopoiesis in DS, and that one of the contributors is RUNX1. As the observed T21-driven hyperproduction of multipotential immature precursors precedes the bifurcation to lymphoid and myeloid lineages, we speculate that this could create conditions of increased chance for acquisition of pre-leukaemogenic rearrangements/mutations in both lymphoid and myeloid lineages

Correspondence: Professor D Nizetic, Centre for Paediatrics, Blizard Institute of Cell and Molecular Science, Barts and The London, Queen Mary's School of Medicine and Dentistry, 4 Newark Street, Whitechapel, London E1 2AT, UK.

E-mail: d.nizetic@qmul.ac.uk

${ }^{6}$ These authors contributed equally to this work.

Received 23 March 2010; revised 27 May 2010; accepted 10 June 2010; published online 9 August 2010 during foetal haematopoiesis, contributing to the increased risk of both leukaemia types in DS.

Oncogene (2010) 29, 6102-6114; doi:10.1038/onc.2010.351; published online 9 August 2010

Keywords: chromosome 21; trisomy 21; gene expression; Down's syndrome; leukaemia; mouse models

\section{Introduction}

Dissection of the roles of individual genetic elements on HSA21 in the pathogenesis of specific phenotype of Down's syndrome (DS) remains a challenge.

Children with DS, in the first few years of life, have approximately 50-fold higher overall incidence of leukaemias than normal children, and this comprises all types of acute myeloid leukaemia and acute lymphocytic leukaemia (ALL) (Krivit and Good, 1957; Hasle et al., 2000). Transient myeloproliferative disorder (TMD) leading to acute megakaryoblastic leukaemia (AMKL) account for more than half of all myeloid leukaemias in DS, with an $\times 500$ increased incidence relative to euploid children (Zipursky et al., 1994; AlKasim et al., 2002; Taub and Ravindranath, 2002). Among lymphoid leukaemias, the B-cell precursor ALL is the most frequent type, but all other types also have an increased incidence (Hasle et al., 2000; Forestier et al., 2008; Hertzberg et al., 2010). The role of trisomy 21 (T21) and specific roles of a trisomic dose of individual $H S A 21$ genes in these increased leukaemia risks are unknown.

Some aspects of both myeloid and lymphoid leukaemias in DS set them apart from leukaemias of the same type in constitutionally euploid children (Malinge et al., 2009): (i) T21 and in utero acquired mutations in the transcription factor GATA1 are observed as always co-existing in the proliferating cells of DS-TMD and DS-AMKL (Wechsler et al., 2002; Groet et al., 2003; Rainis et al., 2003); (ii) overexpression of the oncogene MYCN is observed in DS--TMD blasts (McElwaine et al., 2004; Hitzler and Zipursky, 2005); and (iii) the DS-ALL, despite being very heterogeneous (and partly 
overlapping with non-DS-ALL) in the repertoire of acquired cytogenetic and molecular changes (Forestier et al., 2008; Lundin et al., 2009), show an increased acquisition of mutations in tyrosine kinase JAK2 (Bercovich et al., 2008; Kearney et al., 2009), and much greater abundance of overexpression and rearrangements in the cytokine receptor CRLF2 (Kearney et al., 2009; Lundin et al., 2009; Russell et al., 2009; Hertzberg et al., 2010), than non-DS-ALL. A hypothetical model was proposed, by which T21 could provide a cellautonomous and embryonic-stage specific proliferative advantage for GATA1 mutant clones (Li et al., 2005). Forced massive overexpression of the HSA21 gene ERG in cultured mouse foetal liver (FL) progenitors showed the potential to cooperate with the GATA1 mutation (Salek-Ardakani et al., 2009), boosting the proliferative phenotype observed in mouse foetal haematopoiesis in the absence of T21, in the GATA1 mutation-knock-in mouse (Li et al., 2005). However, this model cannot explain the increased risk in DS of other leukaemia types (myeloid and lymphoid) that do not acquire GATA1 mutations.

Mouse models of DS (Kirsammer et al., 2008; Carmichael et al., 2009; Alford et al., 2010) develop extramedullary hyperproliferation of megakaryocytes, which has been attributed to the third copy of ERG (Ng et al., 2009), and not RUNX1 (Kirsammer et al., 2008), and is unaffected by the simultaneous introduction of GATA1 mutation (Alford et al., 2010). Human FLs with T21 show abnormal myelopoiesis, with an increased presence and proliferating propensity of the megakaryocytic-erythroid progenitor compartment, even in the absence of GATA1 mutations (Chou et al., 2008; De Vita et al., 2008; Tunstall-Pedoe et al., 2008). This evidence put together suggests a general proliferative propensity conferred by T21 in different haematopoietic compartments at different stages in life.

The increased risk of malignancy in DS is not shared by other tissues and organ systems: on the contrary, most common cancers of solid tissues have a substantially reduced incidence in DS, compared with age-matched cohorts of euploid people (Satge et al., 1998; Hasle et al., 2000; Yang et al., 2002). Epidemiological data would suggest that chromosome 21 contains genes with suppressive role in solid tumours. At least one such gene, ETS-2, has been confirmed to fulfil tumour-suppressive role in colon cancer (Sussan et al., 2008).

Because of this paradoxical relationship of T21 (tumourigenic in all types of leukaemias and tumoursuppressive in most types of solid tumours), we decided to investigate the effects of T21 on early haematopoietic differentiation. We reasoned that any effect on this process, in order to provide a common explanation for the increased risk of both major leukaemia types, would have to arise in the differentiation stages, before the bifurcation to myeloid and lymphoid lineages, in the early haematopoietic cell ontogeny. The first cells with a haematopoietic commitment can be detected in vitro in mesodermal colonies, derived by differentiation of mouse embryonic stem cells (ESCs) (Nakano et al., 1994). This is why we focussed on the early mesodermal colony formation in vitro, using the transchromosomic system (mouse ESCs) bearing an extra human chromosome 21 (HSA21) (Hernandez et al., 1999)).

Though mouse ESCs differ from human ESCs in some components of molecular circuitry, the effects of the supernumerary human chromosome 21 in transchromosomic mouse ESCs recapitulate many molecular and cellular phenotypes observed in human cells from T21 foeti: (i) transchromosomic ESCs show a reduction in the levels of the RE-1 silencing transcription factor (NRSF/REST) (Canzonetta et al., 2008), and reduced neurogenesis with abnormally branching neurites (Mensah et al., 2007; Canzonetta et al., 2008) as do neural stem cells from human T21 foeti (Bahn et al., 2002); (ii) the control of NRSF/REST levels can be attributed to the HSA21 gene DYRK1A in transhromosomic ESCs, mouse neural progenitor cells and human lymphocytes (Canzonetta et al., 2008; Lepagnol-Bestel et al., 2009) and (iii) quantitative proteome changes observed in transchromosomic ESCs recapitulate those in human foetal tissues with T21 (Wang et al., 2009). In addition, the transchromosomic ESCs provide a novel genetic dissection system (something that cannot be achieved even in human T21 iPS that has been recently established (Park et al., 2008)), in allowing modelling of selective reduction-to-disomy of individual supernumerary HSA21 genes. This can be achieved using humanspecific small interfering RNA reagents, thereby examining the causative effects of the trisomy of one HSA21 gene at a time, while maintaining the rest of the chromosome in trisomy (Canzonetta et al., 2008).

\section{Results}

Transchromosomic (T21) ESCs generate a higher proportion of haemogenic endothelial cells than wild-type ESCs

Haematopoietic differentiation of the transchromosomic ESC line 47-1 that contains an entire HSA21 on the background of the mouse ESC line D3 (Hernandez et al., 1999) was achieved following an established protocol (Era et al., 2000; Eto et al., 2003). Colonies at day 5 of differentiation were harvested and analyzed for the expression of several markers of the haematopoietic stem cell (HSC) compartment and of haematopoietic lineage progenitors (Akashi et al., 2000). Assessment of the transcriptional profile suggested that the predominant haematopoietic population within the colonies was comprised of HSCs and lineage non-restricted cells (Figure 1a). It had been shown that in vitro generation of HSCs from ESCs proceeds through the formation of a mesodermal precursor characterized by the onset of expression of Flk-1 and Tie-2 (Shalaby et al., 1997; Lugus et al., 2009), followed by the appearance of a transient common precursor of the endothelial and haematopoietic cells, the haemangioblast (Choi et al., 
1998). The haemangioblast has been identified in 'in vivo' and 'in vitro' differentiation of both mouse and human ES cells (Jaffredo et al., 2005; Park et al., 2005), and has been recently shown to arise from the haemogenic endothelial cells (Lancrin et al., 2009). At the level of immunophenotype, these cells express high levels of Tie-2 and c-Kit and are CD41 negative (Lancrin et al., 2009).

In this study, we show that at day 5 of in vitro haematopoietic differentiation, a stage characterized by the formation of mesodermal colonies with haematopoietic potential, the transchromosomic ESCs line 47-1 presents an increase in expression of some markers characteristic of the haemogenic endothelium when compared with the parental cell line D3 (Figure 1bi and ii). Flk-1 showed a substantial increasing trend, though it did not reach statistical significance, while Tie2 and c-Kit were both significantly increased in T21 cells ( $t$-test, $P$-values $=0.02$ and 0.009 , respectively). Gata-2, a master regulator of embryonic and early definitive haematopoiesis (Lugus et al., 2007), was found to be significantly increased as well $(t$-test, $P$-value $=0.03)$. The markers of committed endothelial cells Pecam and Vegf were also compared between the differentiating 47-1 transchromosomic cells and the D3 parental cells, and no difference in expression values was observed (Figure 1biii). The increase in mRNA levels was also reflected in an increase of the $\mathrm{c}-\mathrm{Kit}^{+} \mathrm{CD} 41^{-}$cell population as shown by fluorescence-activated cell sorting analysis (Figures $1 \mathrm{c}$ and $\mathrm{d}$, $t$-test, $P=0.009$ ). Taken together, these data suggest that mesodermal colonies derived from 47-1 cells contain more intermediate precursors with haematopoietic potential than the control colonies.

As the data indicated that a supernumerary HSA21 affects levels of markers crucial to the ontogenesis of HSCs, we reasoned that this should have consequences on the functional ability of HSCs/immature haematopoietic progenitor cells. In order to examine this hypothesis, we compared the +HSA21 (47-1) and normal mesodermal colonies in their potential to generate haemogenic progenitors by limited-dilution assay (Figures 2a and b). Mesodermal colonies at day 5 of the differentiation protocol were trypsinized, dissociated and replated at a density of 500 cells/plate in a 96-well plate containing a fresh layer of OP9 cells (Figure 2a). The number of haematopoietic colonies so generated by the + HSA21 cells (47-1) was significantly higher than the control (D3) (Figure 2b, $t$-test, $P$-value $=0.03)$. These data suggest that mesodermal colonies derived from T21 ESCs generate an increased proportion of haemogenic endothelial cells resulting in the higher numbers of committed HSCs, than the normal control ESCs.

\section{Transchromosomic (T21) ESCs generate a higher proportion of immature multipotent haematopoietic progenitors than wild-type ESCs}

Next, a colony-forming cell assay was performed to compare the ability of the haematopoietic progenitors derived from + HSA21 ESC (47-1) and the normal parental cell line D3 to form colonies of different blood lineages. We scored for colonies of three different types: erythroid (BFU-E), granulocytes-macrophages (CFUGM) and mixed (CFU-GEMM) (schematic plan and examples of colony morphology in Figure 2). The ability of the trisomic haematopoietic progenitors to form erythroid and myeloid colonies did not significantly differ from the control D3 progenitors. However, the number of mixed colonies, which represents HSC-like cells with secondary replating and self-renewal capacity to generate multipotent haemogenic progenitors of different lineages (Broxmeyer et al., 2003), was dramatically increased in 47-1 compared with the control (Figure 2c, $t$-test, $P$-value $<0.001)$. Together with the increase observed in $47-1$ cells in the limited dilution experiment (Figure 2b), these findings strongly argue that $\mathrm{T} 21$ increases the number of immature multipotent haematopoietic progenitors generated in vitro from ES cells.

\section{Increases in c-Kit/Tie-2 and Gata-2 expression are attributable to two separate regions on HSA21}

In order to prove that the molecular changes observed in 47-1 are not simply an artefact of a specific cell line, we generated mesodermal colonies from other

Figure 1 Assessment of the transcriptional and cell-surface profile of day 5 mesodermal colonies generated from transchromosomic ES cells: T21 ESCs produce an increased number of haemogenic endothelial cells. (a) qRT-PCR measurements of mRNA levels of several markers of the haematopoietic stem cell compartment (HSCs) and of lineage progenitors such as the common myeloid progenitors (CMP), the granulocyte-macrophage progenitors (GMP) and the megakaryocyte-erythroid progenitors (MEP). Symbols depict relative amounts of mRNA in each population relative to mGapdh: less than $0.001(-) ; 0.001-0.01( \pm) ; 0.01-0.1(+) ; 0.1-100(++) ;>100(+++)$. (b) qRT-PCR analysis of mRNA levels in day 5 mesodermal colonies derived from D3 and 47-1. Mean mRNA levels of the gene of interest are expressed as fold changes of levels in D3 cells. Error bars indicate the s.e.m. (i) Markers of mesodermal differentiation. A significant difference was observed in the transcript levels Tie-2 $(t$-test; $P$-value $=0.02)$. Values are the mean of three and six independent experiments for Flk-1 and Tie-2, respectively. (ii) Markers of the HSC/immature haematopoietic precursor compartment. A significant difference was found in the expression of c-Kit and Gata-2 between D3 and 47-1 ( $t$-test; $P$-value $=0.009$ and 0.03 , respectively). Data shown are from nine independent experiments. (iii) Markers of endothelial differentiation. No significant difference in the levels of Pecam and Vegf was observed between colonies derived from D3 and 47-1 at day 5 of differentiation. (c) FACS analysis of colonies derived from ESCs D3 and 47-1 at day 5 of differentiation. Staining was performed with anti-CD41-FITC and anti-c-Kit-APC. Data were collected on a LSRII (BD Biosciences, Oxford, UK) instrument and analyzed with FlowJo software version 8.1. Two-colour fluorescence dot plots are shown for D3 and 47-1. (d) Quantification of the c-Kit ${ }^{+} \mathrm{CD} 41^{-}$and of the $\mathrm{c}-\mathrm{Kit}^{+} \mathrm{CD} 41^{+}$population. (i) is showing the frequency of c-Kit ${ }^{+} \mathrm{CD} 41^{-}$cells and (ii) is showing the frequency of $\mathrm{c}-\mathrm{Kit}^{+} \mathrm{CD} 41^{+}$cells in both D3 and 47-1. The frequency of cells positive for c-Kit and negative for CD41 was significantly higher in the trisomic cells than in the control $(t$-test; $P$-value $=0.009)$. Data shown in both charts represents the average percentage of three independent experiments. Error bars indicate s.e.m. A full colour version of this figure is available at the Oncogene journal online. 
transchromosomic ES cell lines carrying smaller portions of HSA21 (43-Q, 40-2 and 46-1) (Hernandez et al., 1999). A detailed analysis of the genomic content of these cells was carried out using a high-resolution comparative genomic hybridization array (HG-18-CHR21 tiling oligo arrays from NimbleGen (Waldkraiburg, Germany) at $70 \mathrm{bp}$ average probe density interval, giving a $3500-\mathrm{bp}$ resolution). Examples of the tiling array a

\begin{tabular}{|c|c|}
\cline { 2 - 2 } \multicolumn{1}{c|}{} & DAY 5 colonies \\
\hline SCL & + \\
\hline GATA2 & +++ \\
\hline C-KIT & ++ \\
\hline Tie-2 & $+/-$ \\
\hline C/EBP & $+/-$ \\
\hline PU.1 & $+/-$ \\
\hline FLK-1 & $+/-$ \\
\hline FLI-1 & + \\
\hline NF-E2 & - \\
\hline GATA1 & - \\
\hline EpoR & - \\
\hline
\end{tabular}

C
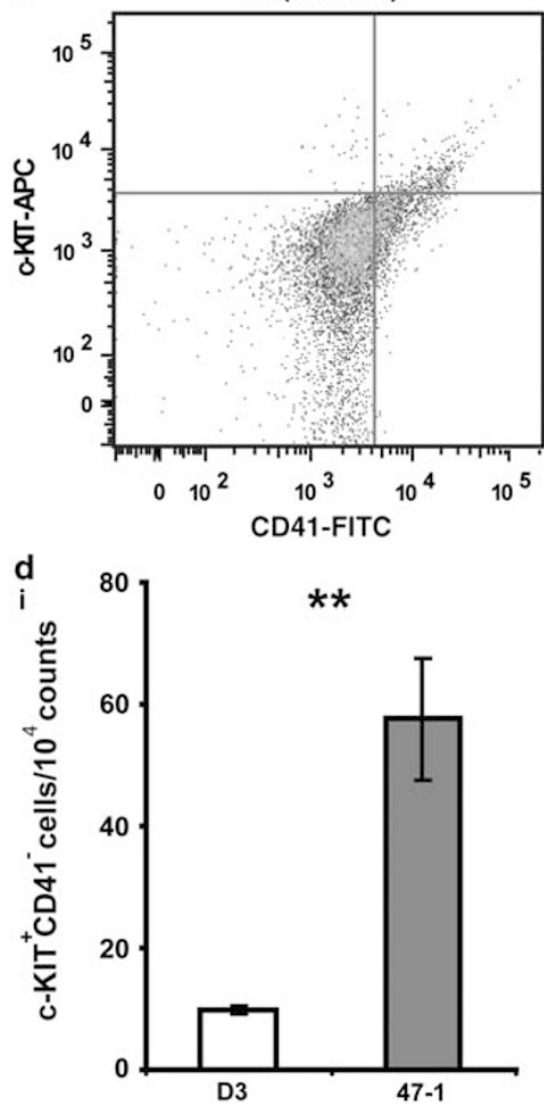

$\square$ D3 normal day5 mesodermal colonies

$\square$ 47-1 (+HSA21) day5 mesodermal colonies
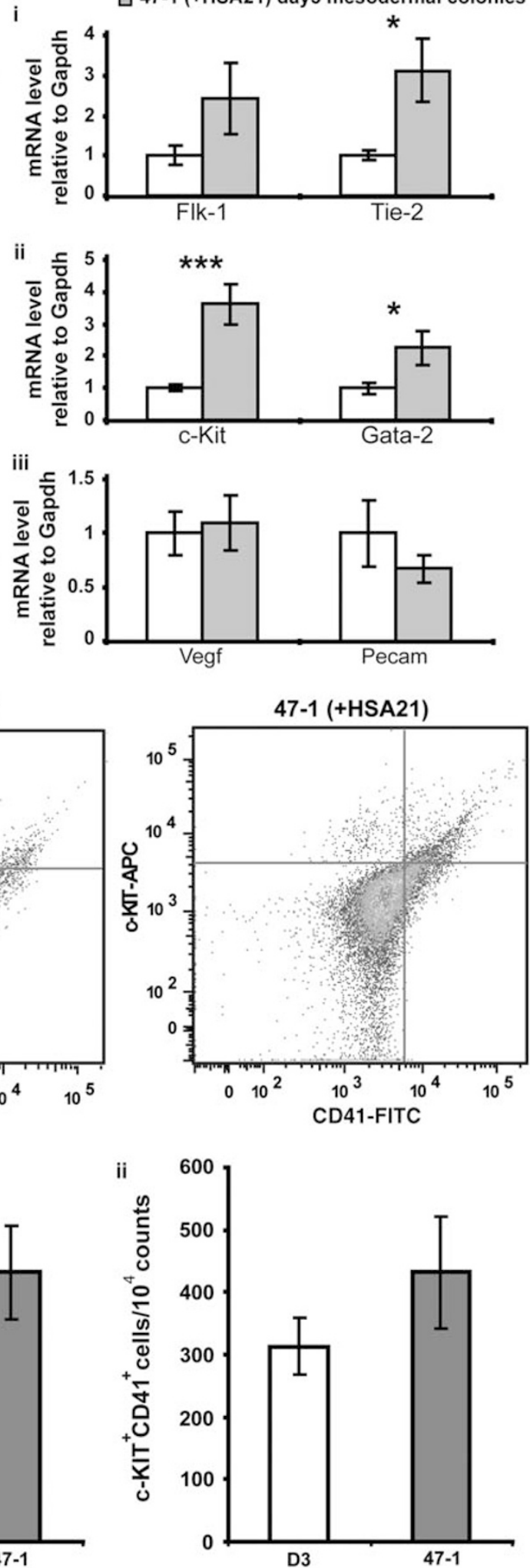

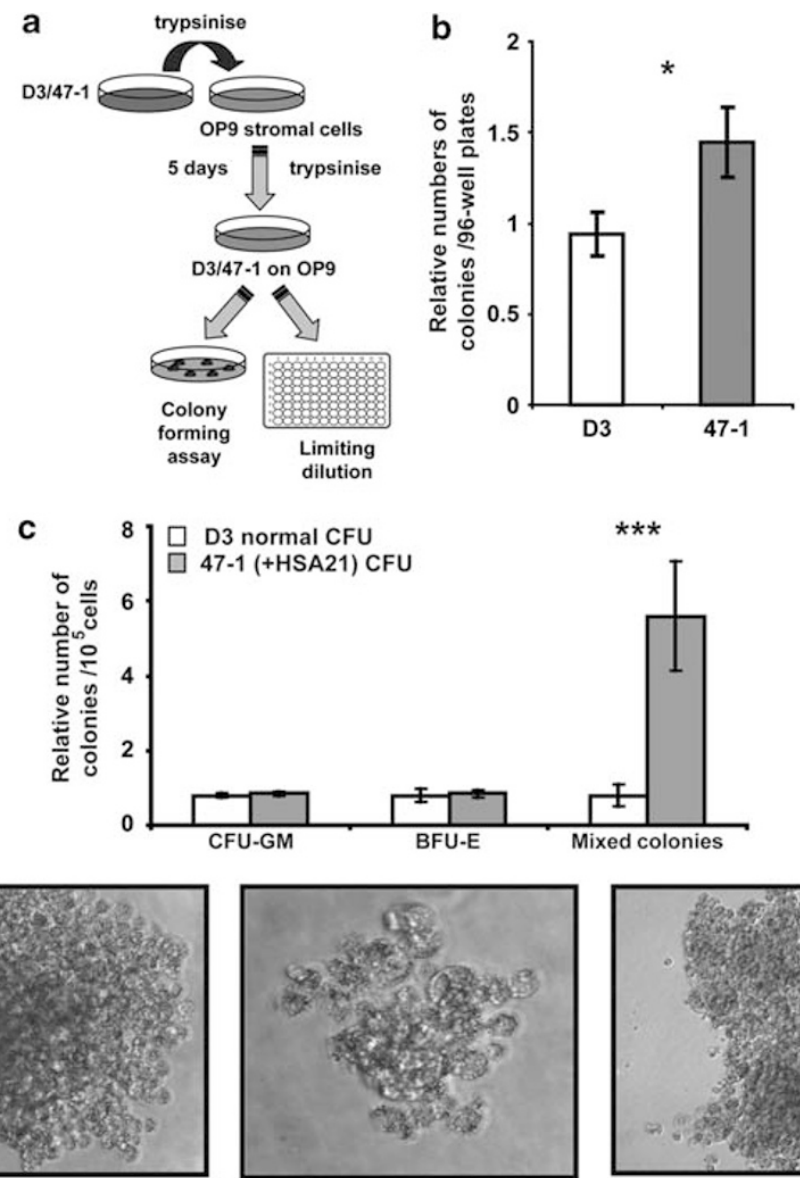

D3 normal CFU 47-1 (+HSA21) CFU
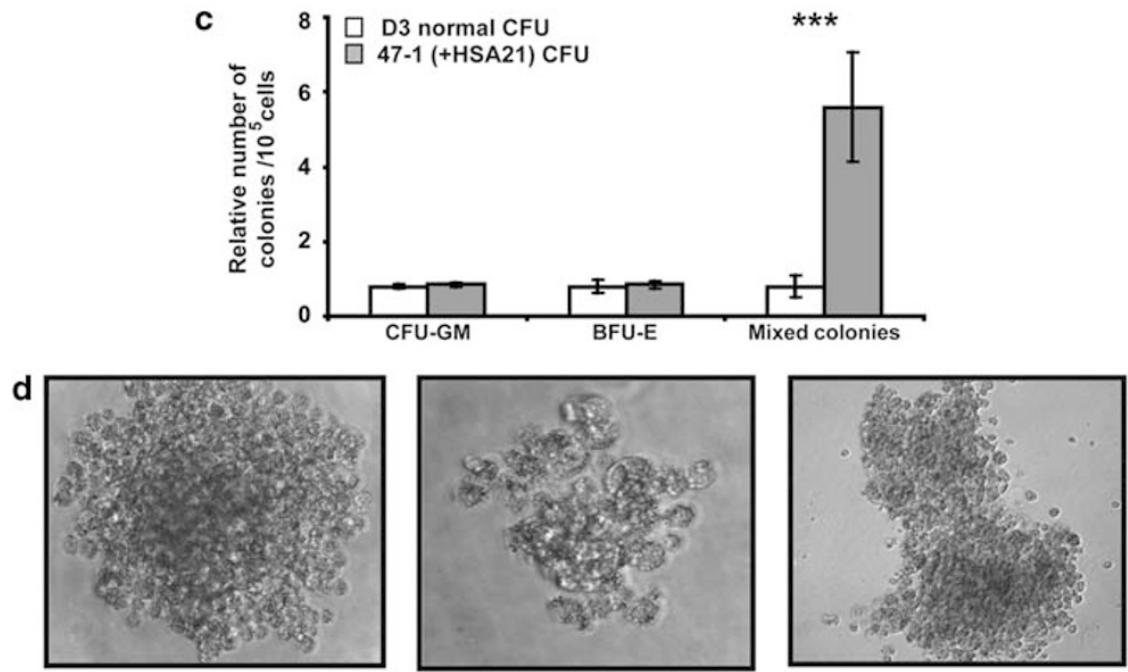

Figure 2 Functional analysis of haematopoietic progenitors derived from the transchromosomic and the parental ES cell lines. (a) Schematic of the assays used for the functional analysis of day 5 colonies derived from 47-1 (+ HSA21) and D3 (euploid) ES cell lines. In brief, the limited-dilution assay day 5 mesodermal colonies were treated with trypsin, counted and replated at a density of 500 cells/plate in a 96-well plate on a fresh layer of OP9 cells. The number of haematopoietic colonies generated from D3 cells and 47-1 cells under these conditions was assessed at day 12. For the colony-forming assay, cells obtained from day 5 mesodermal colonies were seeded on a fresh OP9 layer in 6-well plates. At day 8 of differentiation, the developing haematopoietic cells were harvested and plated in methylcellulose-based medium supplemented with IL-3, IL-6 and EPO. Colonies were counted and classified according to morphology on day 14. (b) Bar graph representing the average number of 47-1 (+ HSA21) colonies relative to the average number of D3 (euploid) colonies counted in ten 96-well plates (five independent cultures were seeded in duplicate). $t$-test $P$-value $=0.03$, error bars indicate s.e.m. (c) Colony-forming unit (CFU) assay. Bar chart showing the average number of myeloid colonies, erythroid colonies and mixed colonies in three independent experiments, normalized in each case to the value obtained for the normal, D3 ESCs. Error bars indicate s.e.m. A very high statistically significant difference was detected between 47-1 (+ HSA21) and D3 (euploid) cells in the number of mixed colonies $(t$-test; $P$-value $<0.001)$. (d) Morphology of colonies generated from haematopoietic progenitors in semisolid medium supplemented with IL-3, IL-6 and EPO, following the Methocult protocol criteria. The figure shows the three types of colonies scored at day 14 after seeding in semi-solid medium. Pictures were taken using a light microscope with an $\times 20$ objective.

hybridization results for these lines can be seen in Supplementary Figure S1. Figure 3a shows mRNA levels of Tie-2, c-Kit and Gata-2 in mesodermal colonies derived in parallel from the panel of partially trisomic ESCs. 43-Q ESCs contain a very large proportion of the genes on HSA21, but show two deletions, which affect more than $5 \mathrm{Mb}$ of HSA21 DNA. These cells present a molecular signature that is very similar to that shown by $47-1$ cells, with levels of mRNA for Tie-2, c-Kit and Gata-2 significantly increased compared with the parental D3 control (Figure 3a, $t$-test $P$-values $=0.03,0.018$ and 0.007, respectively). 40-2 ES cells instead are characterized by bigger deletions (Figure 3b), including genes known to have a role in haematopoiesis, such as $R U N X 1, E R G$ and ETS-2. Transcriptional analysis of day 5 colonies generated by this cell line did not show upregulation of
mRNA levels for Tie-2 or c-Kit, but it kept the same significant increase in Gata-2 levels compared with the D3 euploid control (Figure 3aiii, $t$-test, $P$-value $=0.01$ ). 46-1 ES cell line contains only a small $0.5-\mathrm{Mb}$ stretch of HSA21 comprising of five genes and did not reproduce any of the phenotypes (Figure 3a). These data demonstrate that alteration in the levels of mRNA for the markers analyzed is not an artefact specific to the 47-1 cell line, but is reproducible (totally or partially) in at least three transchromosomic ES cell lines with a defined HSA21 content. Data also suggest that increase in c-Kit and Tie- 2 on one hand, and increase in Gata-2 on the other hand, may represent two separate derangements, caused by the action of genes on two different trisomic regions on HSA21 during in vitro differentiation of ESCs (Figure 3b). 
a
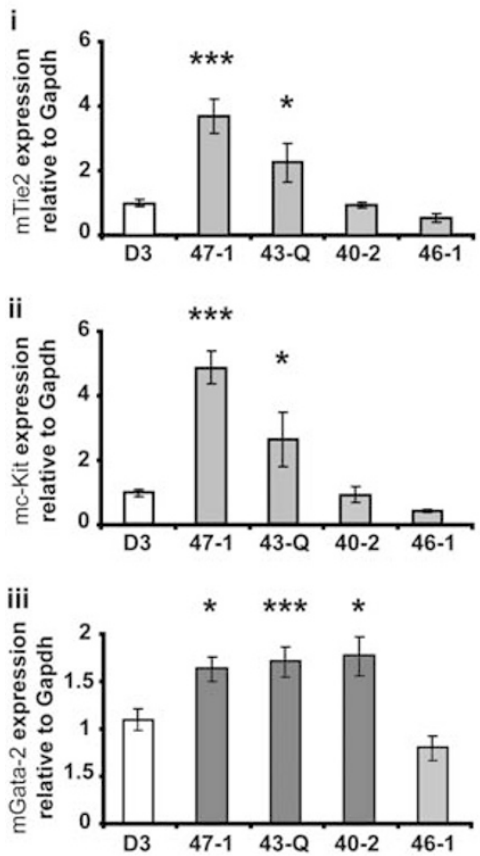

b

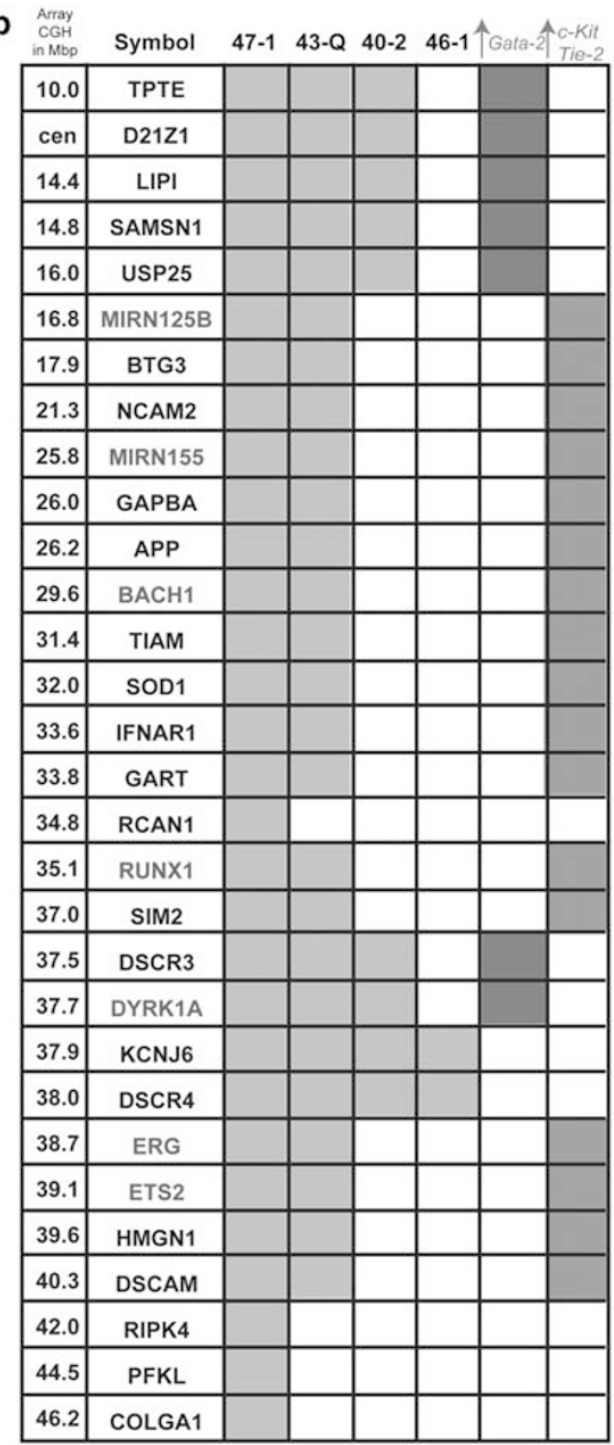

Figure 3 Genetic dissection of HSA21 for the role in mesodermal colony haematopoietic disturbance using partially trisomic ES cell lines. (a) Comparison of the molecular changes observed in + HSA21 ES cell line 47-1, across a panel of partially trisomic ESC lines, 43-Q, 40-2 and 46-1. Bar charts show the average mRNA levels of a minimum of three independent experiments. Data are represented as fold change relative to levels in D3 parental cells. Error bars indicate s.e.m. Levels of Tie-2 and c-Kit mRNA were significantly upregulated in 43-Q, but not in 42-0 and 46-1 (i and ii), compared with the D3 control ( $t$-test; $P$-value $=0.018$ and 0.03 , respectively). (iii) Levels of Gata-2 mRNA were significantly increased in both 43-Q and 42-0, but not in 46-1, compared with the D3 euploid control $(t$-test; $P$-value $=0.007$ and 0.01 , respectively). (b) Characterization of HSA2 1 content of the transchromosomic ES cell lines. Data obtained from HR-CGH array. Light grey bars indicate that a given gene on HSA21 is present in the ES cell line; white bars indicate that the gene is absent. Regions that might be responsible for the increased Gata-2 and the increased c-Kit/Tie-2 phenotypes of mesodermal colonies are highlighted in red and blue respectively. In purple are indicated other HSA21 genes that may be contributing to the c-Kit and Tie-2 disturbance because of their published link with myelo-erythropoiesis.

A third copy of RUNX1, but not ERG or ETS-2, is necessary for the c-Kit/Tie-2 increase

The effects of the increased c-Kit and Tie-2 levels in mesodermal colonies were assigned to the trisomic dose of HSA21 regions that include genes known to have a prominent role in haematopoiesis, such as $R U N X 1$, $E R G$ and ETS-2. Next, we decided to take advantage of the possibility of restoring the diploid dose of one gene at a time on HSA 21 by specifically silencing its third human copy, to test if the causative role for the aberrantly high mesodermal colony transcript levels could be pinpointed to any of the candidate genes. 47-1 ES cells were transfected with human-specific RNAi for a given HSA21 gene or non-targeting RNAi control, and allowed to differentiate up to the mesodermal colony stage. After 5 days of differentiation, cells were harvested, and RNA extraction and qRT-PCR were performed. As can be seen in Figure 4a, the third human copy of RUNX1 was effectively silenced, with little or no effect on the level of mouse RUNX1 transcript, and this silencing lasted at least for 3 days. Levels of c-Kit were significantly lower compared with the 

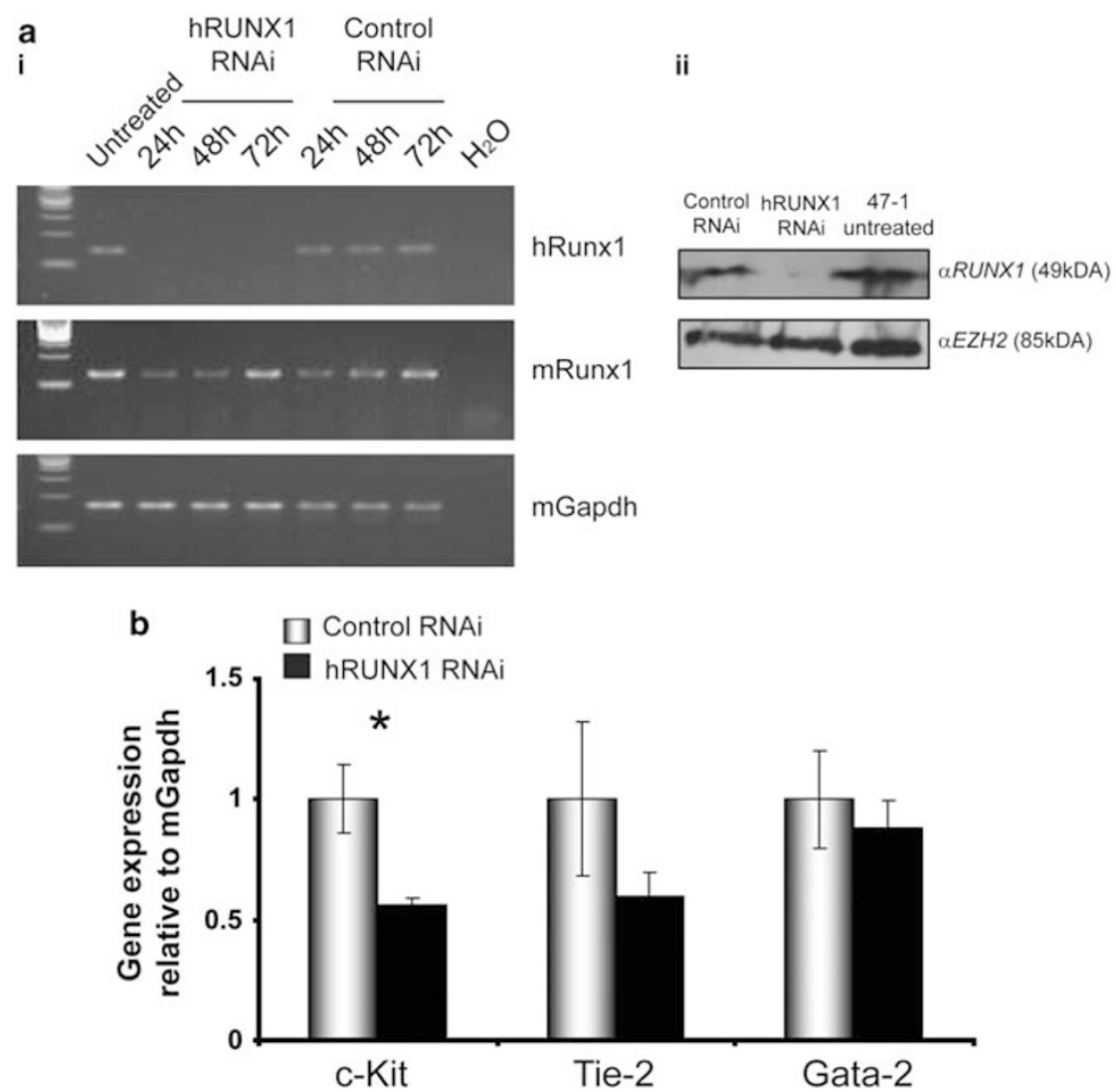

Figure 4 Effects of the reduction of RUNX1 to disomy in differentiating + HSA21 ESCs (a) (i) RT-PCR analysis performed on cDNA extracted from untreated 47-1 (+ HSA21), 47-1 transfected with RNAi oligonucleotides targeting hRUNX1 or with nontargeting RNAi control at different time points. RT-PCR was performed on the same samples with primers specific for hRUNX1, mRunxl and mGapdh. Cells were harvested for total RNA extraction at the indicated time points after transfection. (ii) Western blot performed on untreated 47-1, 47-1 transfected with oligos targeting hRUNX1 and non-targeting oligos. Nuclear extracts were generated from cells harvested $72 \mathrm{~h}$ after transfection. The membrane was probed with a mouse monoclonal antibody anti-RUNX1 and with a rabbit polyclonal antibody against the mouse nuclear protein EZH2 was used as a loading control. (b) The qRT-PCR analysis of mRNA levels for c-Kit, Tie-2 and Gata-2 in day 5 mesodermal colonies derived from 47-1 cells, transfected with RNAi targeting hRUNX1 or non-targeting RNAi control. The mRNA levels were measured 6 days post transfection. Bar charts represent the mean mRNA levels normalized to mGapdh and relative to control samples transfected with non-targeting RNAi sequence $(n=3)$. Error bars indicate s.e.m. There was a significant reduction $(t$-test; $P$-value $=0.04)$ of the levels of c-Kit in the hRUNX1 RNAi compared with the control.

non-targeting control when hRUNX1 was silenced; Tie2 levels were diminished, but did not reach significance, while Gata-2 was unaffected (Figure 4b), as would be predicted from the data obtained using the partial T21 ESC line panel (Figure 3). ERG and ETS-2 RNAi did not show any significant difference from the scrambled RNAi controls (Supplementary Figure S2). Our data therefore suggest that the third copy of RUNX1, but not ERG or ETS-2, is necessary in the context of T21, to account for the observed perturbation of c-Kit and Tie-2 in the early haematopoietic differentiation.

\section{Human FLs with T21 have augmented levels of haematopoietic markers compared with euploid controls} To gain insights into the correlates of the observed molecular changes in human FL haematopoiesis, qRTPCR was used to quantify the level of expression of a panel of genes in RNA extracted from primary samples. Six T21 FLs were compared with euploid controls best matched for sex and gestational age. Samples were frozen tissues from therapeutically terminated T21 or euploid pregnancies, and they were all from the second trimester. Initially, all RNA samples were screened for the presence of mutations or splicing changes in the GATA-1 transcript by RT-PCR and sequencing (data not shown), and all were found to have a wild-type sequence for GATA-1. Markers analyzed included CD34, C-KIT, CD41, PU.1, IGLL-1 and RUNX1 (Figure 5). These markers are expressed predominantly or exclusively in haematopoietic lineage cells, and not in other cell types in the FL. PU.1 is a marker of both myeloid and lymphoid progenitor lineages, whereas IGLL1 is strongly expressed only in pre-B lymphocyte precursors, in a lineage-restricted manner. The expression level of CD34 mRNA was on the border of detectability, and could not be quantified with confidence (not shown). RUNX1, PU.1 and C-KIT mRNA levels were significantly higher in the T21 FLs than in the euploid controls (Figure 5, $P$-value $=0.01,0.03$ and 

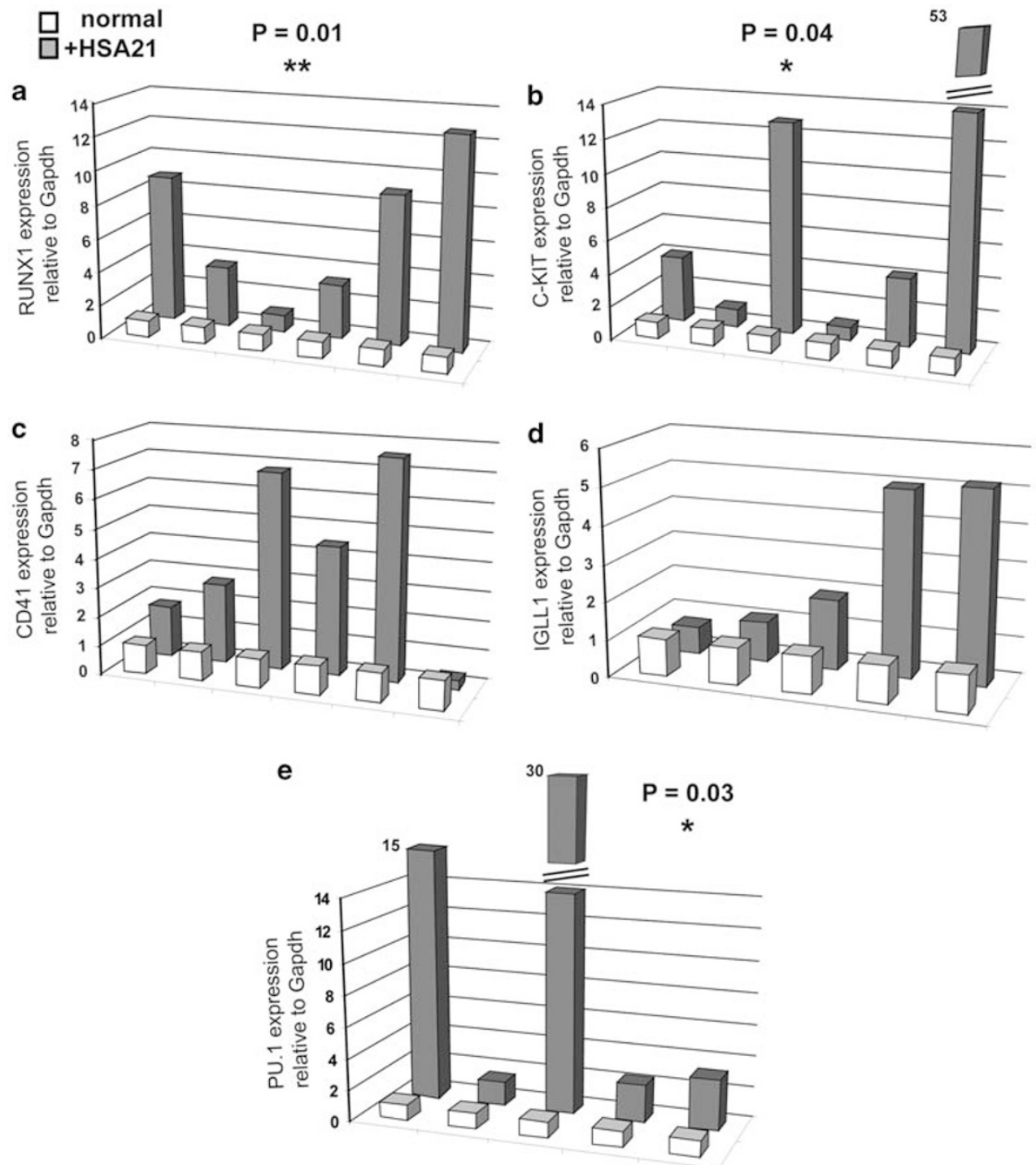

Figure 5 Human FL with trisomy 21 shows increased levels of early haematopoietic markers. qRT-PCR analysis of mRNA levels for RUNX-1, C-KIT, CD41, PU1 and IGLL-1 in FLs from Down's syndrome (DS) and matched euploid controls. Data are presented as ratios of mRNA levels for each DS and its matched euploid control. Significance was calculated by Wilcoxon's signed-rank test. Levels of RUNX1, PU.1 and C-KIT were found to be significantly higher in DS compared with euploid samples $(P$-value $=0.01,0.03$ and 0.04 , respectively).

0.04, respectively) using Wilcoxon's signed-rank tests performed on the six-matched pairs. CD41 and IGLL-1 showed a consistent trend to be higher in T21 than in normal euploid samples, but did not reach statistical significance. Taken together, these data suggest that the in vitro phenotypes we observed using mouse transchromosomic ESCs (Figures 1-5) do represent a valid model for some effects of $\mathrm{T} 21$ on human foetal haematopoiesis.

\section{Discussion}

Increased levels of Gata-2 observed in mesodermal colonies (Figure 1b), though only slightly over twofold, could be responsible for the initial disturbance of haematopoietic differentiation in our system. It has been demonstrated that, with the same differentiation protocol, using coculture with OP9 stromal cells, conditionally induced overexpression of GATA-2 (tenfold) caused enhanced production of haemangioblasts (Lugus et al., 2007) and haematopoietic progenitors (Kitajima et al., 2002, 2006). The increase in Gata-2 mRNA levels by the 47-1, 43-Q and 40-2 cells, but not 46-1 ES cells (Figure 3a), is attributable to trisomy of two different regions on HSA21 (Figure 3b, red column). The distal of the two regions contains DYRK1A, which has been previously shown to have an effect on derangement of the pluripotency of ESCs (Canzonetta et al., 2008). The proximal region corresponds to the pericentromeric region, the same segment 
6110

of HSA21 that was found by multiple studies to harbour frequent chromosome rearrangements and an increased disomic homozygosity of the DNA markers in DSTMD and DS-AMKL, compared with DS without leukaemia (Niikawa et al., 1991; Shen et al., 1995; Ohta et al., 1996; Cavani et al., 1998; Korbel et al., 2009). Conversely, trisomy of one or more genes, which are present in 47-1 and 43-Q, but absent in 40-2 and 46-1, is required for regulating the levels of Tie-2 and c-Kit. Interestingly, among these genes there are some important regulators of haematopoiesis and leukaemogenesis, such as ERG, ETS-2 and RUNX1 (Figure 3b, blue column), which makes them natural candidates for this role. Our RNAi data (Figure 4, Supplementary Figure S2) suggest that the third copy of RUNX1, but not ERG or ETS-2, is necessary in the context of T21 to account for the observed perturbation of the early haematopoietic differentiation. These results are in concordance with data reported for the systems with induced massive overexpression of these genes. Although ERG was found, on massive overexpression to promote megakaryopoiesis in the cell lines (Rainis et al., 2005), and both ERG and ETS-2 were found to cooperate with GATA1 mutation in boosting megakaryocyte hyperproliferation (Salek-Ardakani et al., 2009; Stankiewicz and Crispino, 2009), RUNX1 conditional overexpression in vitro using the same OP9-based differentiation system enhanced the production of HSC and immature progenitors of all myeloid, and most significantly (on addition of Flt3-ligand) also B-lymphocyte progenitors (Sakai et al., 2009). Haploinsufficiency of RUNX1 produces a mouse with reduced HSC and early haematopoiesis (Cai et al., 2000). These data combined with the presented results (Figures 2-5) point to RUNX1 as a significant candidate for the contribution to the hypothetical common mechanism behind the increased risk of myeloid and lymphoid leukaemias in DS. When driven by the GATA1 promoter in vivo, overexpression of RUNX1 was found to be proleukaemogenic in the myeloid lineage, and it produced the closest representation so far of a DS-TMD in a mouse model: increased numbers of leucocytes and CD61 ${ }^{+}$cells in neonates, but not in 8-month-old mice (Yanagida et al., 2005). We cannot rule out the contribution of other HSA21 genes in the generation of the c-Kit and Tie-2 disturbance such as those marked purple in the list of genes in Figure $3 b$, because of their published link with myelo-erythropoiesis (Toki et al., 2005; O'Connell et al., 2008; Klusmann et al., 2010) Encouragingly, our in vitro phenotype using mouse ESCs has an in vivo correlate in the human foetal haematopoiesis: CD34+ cells from FLs with T21 were recently reported to have a markedly increased clonogenicity of several myeloid lineage progenitors, including higher numbers and replating efficiency of the CFU-GEMM (mixed) immature progenitors (Tunstall-Pedoe et al., 2008).

The increased levels of C-KIT that we find in T21-FL (Figure 5) would suggest that committed HSCs and/or immature haematopoietic precursors are more numerous in DS-FLs than in euploid controls, as the expression of C-KIT in human FLs is restricted to the
$\mathrm{CD} 8^{+}$stem cell compartment (Teyssier-Le Discorde et al., 1999). Interestingly, a recent report has found that the level of C-KIT and SCF/C-KIT signalling (proliferative stimulation by SCF and inhibition by imatinib) were significantly increased in primary DS-TMD blasts (Toki et al., 2009). The increased levels of RUNX1 that we find in T21 FLs appear to be highly significant, and on an average $>5 \times$ the euploid liver value, (Figure 5), overall much higher than would be predicted by a mere $1.5 \times$ trisomic increase. The RUNX1 level increase in the range of $1.5 \times$ though on just a few samples, has been reported for the isolated $\mathrm{CD} 34^{+}$cells from human T21 FLs (Tunstall-Pedoe et al., 2008). This suggests that our result is more likely representing a much higher overall proportion of RUNX1-expressing cells in the T21 FLs, rather than a disproportionately increased level of RUNX1 per cell. As only haematopoietic (HSC, and differentiating myeloid and lymphoid) cells are expected to express RUNX1 (Levanon and Groner, 2004), the data suggest that T21 FLs have much more (3-4 $\times$ ) active haematopoiesis than euploid controls. As RUNX1 levels were not found to be disproportionately increased in GATA1-mutated DS-TMD blasts (McElwaine et al., 2004), we suggest that the trisomic increase of RUNX1 dose alone contributes to the initial disturbance that sets off a stochastic pathogenetic process.

\section{Stochastic model of leukaemogenesis in DS}

So far, the role of HSA21 genes in the pathogenesis of DS-leukaemias is uncertain. One model postulates that trisomic overdose of unknown HSA21 genes provides a selective proliferative advantage for the clonal expansion of cells that acquired pre-leukaemogenic mutations, such as GATA1 in DS-AMKL/TMD or JAK2 in DSALL (Li et al., 2005; Malinge et al., 2009). Recent findings (Chou et al., 2008; De Vita et al., 2008; Tunstall-Pedoe et al., 2008) suggest a model in which hyperproliferative tendency of the megakaryocyte precursors caused by $\mathrm{T} 21$ precedes the accumulation of GATA1 mutations (Tunstall-Pedoe et al., 2008). Combining the data presented (Figures 1-5) with the existing literature allows us to extend this view even further, and hypothesize that the trisomic dose of different HSA21 genes contributes to an increased generation of immature haemogenic precursors at multiple levels, acting stochastically to increase the risk of acquisition of preleukaemogenic and leukaemogenic mutations in both lymphoid and myeloid branches (Figure 6). Following from left to right, this diagram combines multiple lines of evidence: (i) trisomy of DYRK1A disturbs ESCs pluripotency and early stem cell fate with increased markers of endodermal and mesodermal lineages (Canzonetta et al., 2008); (ii) trisomy of either the DYRK1A locus and/or the pericentromeric region, or both, causes the increased levels of Gata-2 in mesodermal colonies (Figures 1 and 3); (iii) overexpression of Gata- 2 causes an increase in the numbers of haemogenic endothelial cells $\left(\mathrm{Flk} 1^{+} \mathrm{Tie}-2^{+} \mathrm{c}-\mathrm{Kit}^{+} \mathrm{CD}^{+} 1^{-}\right.$) (Lugus et al., 2007) and (Figures 1 and 2), and it could even 
cause an additional upregulation of RUNX1 expression (due to the presence of Gata-2 at the RUNX1 promoter, (Nottingham et al., 2007)); (iv) increased expression of RUNX1 due to T21 alone, or in addition due to Gata-2 increase, drives stronger the commitment of haemogenic endothelial cells to become HSCs (Zovein et al., 2008; Chen et al., 2009; Lancrin et al., 2009; Sakai et al., 2009), which is why the increase in the level of c-Kit (representing the combined presence of haemogenic endothelial cells and HSCs) can be corrected by the reduction of RUNX1 back to disomy (Figure 4); (v) all this results in increased clonogenicity of haematopoietic progenitors in T21 FLs (Tunstall-Pedoe et al., 2008), and specially accumulation (and increased selfrenewing potential) of immature precursors (Figure 5) and multipotent CFU-GEMM, (Figure 2 and TunstallPedoe et al., 2008), as well as an increased capacity to generate B-lymphocyte precursors (Sakai et al., 2009); (vi) through increased dose of ERG, differentiation of common myeloid progenitors is further skewed towards megakaryocyte-erythroid progenitor lineage (Rainis et al., 2005; Chou et al., 2008; Tunstall-Pedoe et al., 2008) (vii) all these processes increase the chances ('cast dice' symbol in Figure 6) for JAK2, CRLF2, GATA1, JAK3 and other mutations to occur, causing expansions of pre-leukaemic clones; and (viii) these pre-leukaemic clones, (manifesting themselves as DSTMD, when associated with GATA1 mutations), can either accumulate a variety of other tumourigenic hits during early childhood, (similar to most non-DS haematological malignancies) (Forestier et al., 2008; Kearney et al., 2009; Russell et al., 2009), or spontaneously regress and disappear in adulthood. A noticeable exception is the MLL rearrangements that are actually lacking in DS-ALL, reflecting probably another pathogenetic constraint conferred by T21 that needs explanation. Clones with sufficient numbers of additional hits develop full ALL or acute myeloid leukaemia (more than half of acute myeloid leukaemias are GATA1-mutated acute megakaryoblastic leukaemias). The intensity of this stochastic regulation, as well as the fate (nothing, regression, ALL or acute myeloid leukaemia) could depend, in addition to chance, on the subtle inter-individual differences in the level of expression of the relevant HSA21 genes among the DS individuals in population where the disproportionate net increase in specific gene(s) expression in a subset of DS individuals could result from a high expressing allele superimposed on the trisomic dose increase (Prandini et al., 2007). Very sharp increases in levels of haematopoietic markers seen in some T21 FL samples (Figure 5), and great individual variability between samples could reflect this explanation.

Importantly, human RUNX1 is missing from the list of genes trisomic in the Tc1 mouse model of DS, as it was among the $17 \%$ of genes deleted in the ESC line

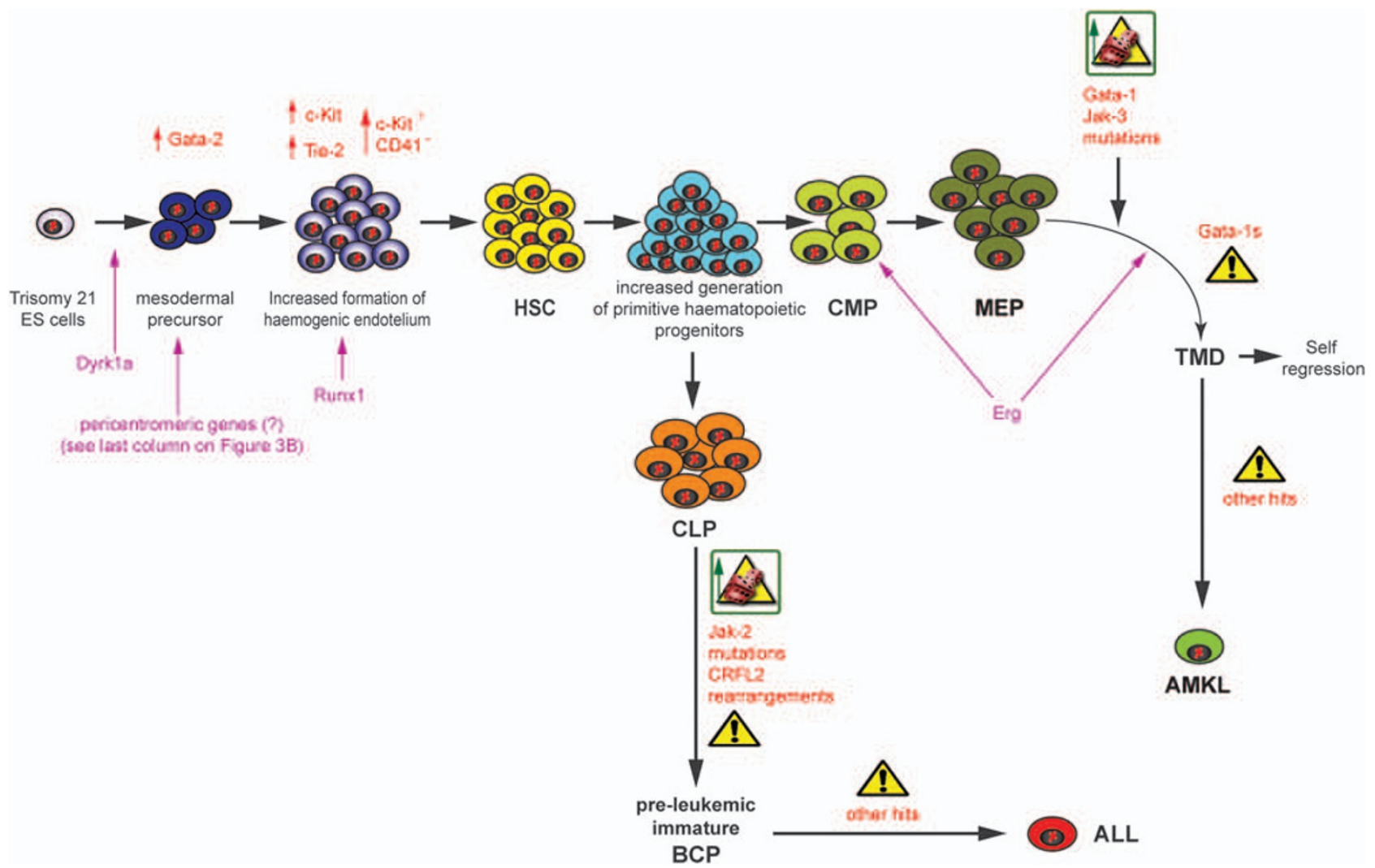

Figure 6 Stochastic model of leukaemogenesis in Down's syndrome (DS), pointing at multiple effects of several trisomic HSA21 genes. The HSA21 genes are shown in purple, measurable effects in red, multiple cell symbols signify hyperproliferation/increased presence of the particular cell type, cast dice symbols represent increased chance of a mutagenic event occurring and the warning sign symbolizes an acquired mutation that has occurred. Refer the 'Discussion' section in text for detailed explanation. 
used to generate the mouse (Alford et al., 2010), and the pericentromeric HSA21 region is missing in other DS mouse models that contain RUNX1 (Olson et al., 2004). Therefore, the in vitro disturbance we observe could not have fully contributed to any DS-leukaemia mouse model analyzed thus far, as none of the models contained all of the co-operating trisomic chromosomal regions.

\section{Materials and methods}

\section{Materials, cells and tissues}

All general reagents, tissue-culture media and primers were supplied by Sigma-Aldrich (Dorset, UK), unless otherwise stated. Transchromosomic ES cells 47 1, 40-2, 43-Q and 46-1 were derived from D3 ES cells by the introduction of all, or parts, of HSA21 via microcell-mediated chromosome transfer (Hernandez et al., 1999). Sequences of primers used for quantitative RT-PCR are available on request. Mouse monoclonal anti-hRUNX1 antibody and rabbit polyclonal anti-mouse EZH2 antibody were from Abcam (Cambridge, UK). FLs were consented terminated human foetal tissue collected by the Galliera Hospital's Tissue Bank or the MRC Foetal Tissue Bank. All archived material was consented for use in research, and the project is covered by the ethical approval from the North East London Health Authority.

\section{ES Cell culture and differentiation}

Pluripotent D3, 47-1, 40-2, 43-Q and 46-1 ES cells were cultured as described (Canzonetta et al., 2008). Minimization of background from feeder cells was obtained by pre-plating, before differentiation or RNA extraction, for 45 min onto nongelatine coated tissue culture flasks. OP9 cells (ATCC (Manassas, VA, USA) CRL-2749) were maintained in freshly prepared minimum essential medium supplemented with $20 \%$ foetal bovine serum (ATCC, 30-2021) and 2mM L-glutamine. Haematopoietic differentiation of the different ES cell lines was performed as previously described (Era et al., 2000; Kitajima et al., 2003). In brief, a confluent layer of OP9 cells was seeded in 6-well plates $16 \mathrm{~h}$ before starting the differentiation protocol. At day 0 each well of a 6-well plate was seeded with $5 \times 10^{4}$ ES cells in OP9 medium. At day 5, cells were trypsinized, supplemented with fresh OP9 medium and plated for $45 \mathrm{~min}$ into T75 tissue culture flasks to remove the stromal cells. The supernatant was collected and RNA was extracted with RNeasy Plus Mini Kit (Qiagen, Crawley, UK).

\section{References}

Akashi K, Traver D, Miyamoto T, Weissman IL. (2000). A clonogenic common myeloid progenitor that gives rise to all myeloid lineages. Nature 404: 193-197.

Al-Kasim F, Doyle JJ, Massey GV, Weinstein HJ, Zipursky A. (2002). Incidence and treatment of potentially lethal diseases in transient leukemia of Down syndrome: Pediatric Oncology Group Study. $J$ Pediatr Hematol Oncol 24: 9-13.

Alford K, Slender A, Vanes L, Li Z, Fisher EM, Nizetic D et al. (2010). Perturbed hematopoiesis in the Tc1 mouse model of Down Syndrome. Blood 115: 2928-2937.

Bahn S, Mimmack M, Ryan M, Caldwell MA, Jauniaux E, Starkey M et al. (2002). Neuronal target genes of the neuron-restrictive silencer
Limiting dilution assay

Cells were harvested by treatment with trypsin at day 5 of haematopoietic differentiation, counted and replated onto a fresh OP9 feeder layer at a density of $5 \times 10^{2}$ cells/plate in a 96-well plate. At day 12, wells were scored under a light microscope for the presence of haematopoietic colonies.

\section{Colony-forming unit assay}

At day 5 of the haematopoietic differentiation protocol, cells were harvested, resuspended to a single cell suspension and replated on a fresh OP9 feeder layer. Three days later, cells were trypsinized again, counted and plated on a semi-solid medium supplemented with cytokines (Methocult, M3434, Stem Cell Technologies, Grenoble, France) at a density of $1 \times 10^{5} /$ dish in $35 \mathrm{~mm}$ dishes. Scoring of the colonies was performed using a light microscope according to the manufacturer's instructions.

\section{RNAi silencing}

RNAi control and transfection protocol were as previously described (Canzonetta et al., 2008), see also Supplementary Methods online.

\section{Protein analysis}

Immunoblot analyses were performed as described previously (Delom et al., 2007), see also Supplementary Methods online.

For all other detail methods, please see the file 'Supplementary Methods', in the online Supplementary Material.

\section{Conflict of interest}

The authors declare no conflict of interest.

\section{Acknowledgements}

We thank Gary Warnes for help with FACS analysis and Mike Kirwan for technical advice. This work was supported by the 'Aneuploidy' Grant from Framework Programme 6 from the EU Commission, and by the Gordon Piller Studentship (05075) and the specialist programme Grant (06003) from the Leukaemia Research Fund-UK. For FL material, we thank the MRC-Foetal Tissue Bank, and The Galliera Genetic Bank-'Telethon Genetic Biobank Network', which is supported by Italian Telethon Grants (Project no. GTB07001). We would also like to thank MRC funding number U117527252.

factor in neurospheres derived from fetuses with Down's syndrome: a gene expression study. Lancet 359: 310-315.

Bercovich D, Ganmore I, Scott LM, Wainreb G, Birger Y, Elimelech A et al. (2008). Mutations of JAK2 in acute lymphoblastic leukaemias associated with Down's syndrome. Lancet 372: 1484-1492.

Broxmeyer HE, Srour EF, Hangoc G, Cooper S, Anderson SA, Bodine DM. (2003). High-efficiency recovery of functional hematopoietic progenitor and stem cells from human cord blood cryopreserved for 15 years. Proc Natl Acad Sci USA 100: 645-650.

Cai Z, de Bruijn M, Ma X, Dortland B, Luteijn T, Downing RJ et al. (2000). Haploinsufficiency of AML1 affects the temporal and spatial 
generation of hematopoietic stem cells in the mouse embryo. Immunity 13: 423-431.

Canzonetta C, Mulligan C, Deutsch S, Ruf S, O’Doherty A, Lyle R et al. (2008). DYRK1A-dosage imbalance perturbs NRSF/REST levels, deregulating pluripotency and embryonic stem cell fate in Down syndrome. Am J Hum Genet 83: 388-400.

Carmichael CL, Majewski IJ, Alexander WS, Metcalf D, Hilton DJ, Hewitt CA et al. (2009). Hematopoietic defects in the Ts1Cje mouse model of Down syndrome. Blood 113: 1929-1937.

Cavani S, Perfumo C, Argusti A, Pierluigi M, Perroni L, Schmiegelow $\mathrm{K}$ et al. (1998). Cytogenetic and molecular study of 32 Down syndrome families: potential leukaemia predisposing role of the most proximal segment of chromosome 21q. Br J Haematol 103: 213-216.

Chen MJ, Yokomizo T, Zeigler BM, Dzierzak E, Speck NA. (2009). Runx1 is required for the endothelial to haematopoietic cell transition but not thereafter. Nature 457: 887-891.

Choi K, Kennedy M, Kazarov A, Papadimitriou JC, Keller G. (1998). A common precursor for hematopoietic and endothelial cells. Development 125: 725-732.

Chou ST, Opalinska JB, Yao Y, Fernandes MA, Kalota A, Brooks JS et al. (2008). Trisomy 21 enhances human fetal erythro-megakaryocytic development. Blood 112: 4503-4506.

De Vita S, Devoy A, Groet J, Kruslin B, Kuzmic-Prusac I, Nizetic D. (2008). Megakaryocyte hyperproliferation without GATA1 mutation in foetal liver of a case of Down syndrome with hydrops foetalis. Br J Haematol 143: 300-303.

Delom F, Emadali A, Cocolakis E, Lebrun JJ, Nantel A, Chevet E. (2007). Calnexin-dependent regulation of tunicamycin-induced apoptosis in breast carcinoma MCF-7 cells. Cell Death Differ 14: 586-596.

Era T, Takagi T, Takahashi T, Bories JC, Nakano T. (2000). Characterization of hematopoietic lineage-specific gene expression by $\mathrm{ES}$ cell in vitro differentiation induction system. Blood 95: 870-878.

Eto K, Leavitt AL, Nakano T, Shattil SJ. (2003). Development and analysis of megakaryocytes from murine embryonic stem cells. Methods Enzymol 365: 142-158.

Forestier E, Izraeli S, Beverloo B, Haas O, Pession A, Michalova K et al. (2008). Cytogenetic features of acute lymphoblastic and myeloid leukemias in pediatric patients with Down syndrome: an iBFM-SG study. Blood 111: 1575-1583.

Groet J, McElwaine S, Spinelli M, Rinaldi A, Burtscher I, Mulligan C et al. (2003). Acquired mutations in GATA1 in neonates with Down's syndrome with transient myeloid disorder. Lancet 361: $1617-1620$

Hasle H, Clemmensen IH, Mikkelsen M. (2000). Risks of leukaemia and solid tumours in individuals with Down's syndrome. Lancet 355: $165-169$.

Hernandez D, Mee PJ, Martin JE, Tybulewicz VL, Fisher EM. (1999). Transchromosomal mouse embryonic stem cell lines and chimeric mice that contain freely segregating segments of human chromosome 21. Hum Mol Genet 8: 923-933.

Hertzberg L, Vendramini E, Ganmore I, Cazzaniga G, Schmitz M, Chalker J et al. (2010). Down syndrome acute lymphoblastic leukemia, a highly heterogeneous disease in which aberrant expression of CRLF2 is associated with mutated JAK2: a report from the International BFM Study Group. Blood 115: 1006-1017.

Hitzler JK, Zipursky A. (2005). Origins of leukaemia in children with Down syndrome. Nat Rev Cancer 5: 11-20.

Jaffredo T, Nottingham W, Liddiard K, Bollerot K, Pouget C, de Bruijn M. (2005). From hemangioblast to hematopoietic stem cell: an endothelial connection? Exp Hematol 33: 1029-1040.

Kearney L, Gonzalez De Castro D, Yeung J, Procter J, Horsley SW, Eguchi-Ishimae M et al. (2009). Specific JAK2 mutation (JAK2R683) and multiple gene deletions in Down syndrome acute lymphoblastic leukemia. Blood 113: 646-648.

Kirsammer G, Jilani S, Liu H, Davis E, Gurbuxani S, Le Beau MM et al. (2008). Highly penetrant myeloproliferative disease in the Ts65Dn mouse model of Down syndrome. Blood 111: 767-775.
Kitajima K, Masuhara M, Era T, Enver T, Nakano T. (2002). GATA-2 and GATA-2/ER display opposing activities in the development and differentiation of blood progenitors. EMBO J 21: $3060-3069$.

Kitajima K, Tanaka M, Zheng J, Sakai-Ogawa E, Nakano T. (2003). In vitro differentiation of mouse embryonic stem cells to hematopoietic cells on an OP9 stromal cell monolayer. Methods Enzymol 365: $72-83$.

Kitajima K, Tanaka M, Zheng J, Yen H, Sato A, Sugiyama D et al. (2006). Redirecting differentiation of hematopoietic progenitors by a transcription factor, GATA-2. Blood 107: 1857-1863.

Klusmann JH, Li Z, Bohmer K, Maroz A, Koch ML, Emmrich S et al. (2010). miR-125b-2 is a potential oncomiR on human chromosome 21 in megakaryoblastic leukemia. Genes Dev 24: 478-490.

Korbel JO, Tirosh-Wagner T, Urban AE, Chen XN, Kasowski M, Dai $\mathrm{L}$ et al. (2009). The genetic architecture of Down syndrome phenotypes revealed by high-resolution analysis of human segmental trisomies. Proc Natl Acad Sci USA 106: 12031-12036.

Krivit W, Good RA. (1957). Simultaneous occurrence of mongolism and leukemia; report of a nationwide survey. AMA J Dis Child 94: 289-293.

Lancrin C, Sroczynska P, Stephenson C, Allen T, Kouskoff V, Lacaud G. (2009). The haemangioblast generates haematopoietic cells through a haemogenic endothelium stage. Nature 457: 892-895.

Lepagnol-Bestel AM, Zvara A, Maussion G, Quignon F, Ngimbous B, Ramoz N et al. (2009). DYRK1A interacts with the REST/NRSFSWI/SNF chromatin remodelling complex to deregulate gene clusters involved in the neuronal phenotypic traits of Down syndrome. Hum Mol Genet 18: 1405-1414.

Levanon D, Groner Y. (2004). Structure and regulated expression of mammalian RUNX genes. Oncogene 23: 4211-4219.

Li Z, Godinho FJ, Klusmann JH, Garriga-Canut M, Yu C, Orkin SH. (2005). Developmental stage-selective effect of somatically mutated leukemogenic transcription factor GATA1. Nat Genet 37: 613-619.

Lugus JJ, Chung YS, Mills JC, Kim SI, Grass J, Kyba M et al. (2007). GATA2 functions at multiple steps in hemangioblast development and differentiation. Development 134: 393-405.

Lugus JJ, Park C, Ma YD, Choi K. (2009). Both primitive and definitive blood cells are derived from Flk-1+ mesoderm. Blood 113: $563-566$.

Lundin C, Davidsson J, Hjorth L, Behrendtz M, Johansson B. (2009). Tiling resolution array-based comparative genomic hybridisation analyses of acute lymphoblastic leukaemias in children with Down syndrome reveal recurrent gain of $8 \mathrm{q}$ and deletions of $7 \mathrm{p}$ and $9 \mathrm{p} . \mathrm{Br}$ J Haematol 146: 113-115.

Malinge S, Izraeli S, Crispino JD. (2009). Insights into the manifestations, outcomes, and mechanisms of leukemogenesis in Down syndrome. Blood 113: 2619-2628.

McElwaine S, Mulligan C, Groet J, Spinelli M, Rinaldi A, Denyer G et al. (2004). Microarray transcript profiling distinguishes the transient from the acute type of megakaryoblastic leukaemia (M7) in Down's syndrome, revealing PRAME as a specific discriminating marker. Br J Haematol 125: 729-742.

Mensah A, Mulligan C, Linehan J, Ruf S, O’Doherty A, Grygalewicz $\mathrm{B}$ et al. (2007). An additional human chromosome 21 causes suppression of neural fate of pluripotent mouse embryonic stem cells in a teratoma model. BMC Dev Biol 7: 131.

Nakano T, Kodama H, Honjo T. (1994). Generation of lymphohematopoietic cells from embryonic stem cells in culture. Science $\mathbf{2 6 5}$ : 1098-1101.

Ng AP, Hyland CD, Metcalf D, Carmichael CL, Loughran SJ, Di Rago L et al. (2009). Trisomy of Erg is required for myeloproliferation in a mouse model of Down syndrome. Blood 115: 3966-3969.

Niikawa N, Deng HX, Abe K, Harada N, Okada T, Tsuchiya H et al. (1991). Possible mapping of the gene for transient myeloproliferative syndrome at 21q11.2. Hum Genet 87: 561-566.

Nottingham WT, Jarratt A, Burgess M, Speck CL, Cheng JF, Prabhakar S et al. (2007). Runxl-mediated hematopoietic stem-cell emergence is controlled by a Gata/Ets/SCL-regulated enhancer. Blood 110: 4188-4197. 
O'Connell RM, Rao DS, Chaudhuri AA, Boldin MP, Taganov KD, Nicoll J et al. (2008). Sustained expression of microRNA-155 in hematopoietic stem cells causes a myeloproliferative disorder. $J$ Exp Med 205: 585-594.

Ohta T, Nakano M, Tsujita T, Abe K, Osoegawa K, Yamagata T et al. (1996). Isolation of a cosmid clone corresponding to an inv(21) breakpoint of a patient with transient abnormal myelopoiesis. Am J Hum Genet 58: 544-550.

Olson LE, Roper RJ, Baxter LL, Carlson EJ, Epstein CJ, Reeves RH. (2004). Down syndrome mouse models Ts65Dn, Ts1Cje, and Ms1Cje/Ts65Dn exhibit variable severity of cerebellar phenotypes. Dev Dyn 230: 581-589.

Park C, Ma YD, Choi K. (2005). Evidence for the hemangioblast. Exp Hematol 33: 965-970.

Park IH, Arora N, Huo H, Maherali N, Ahfeldt T, Shimamura A et al. (2008). Disease-specific induced pluripotent stem cells. Cell 134: 877-886.

Prandini P, Deutsch S, Lyle R, Gagnebin M, Delucinge Vivier C, Delorenzi $\mathrm{M}$ et al. (2007). Natural gene-expression variation in Down syndrome modulates the outcome of gene-dosage imbalance. Am J Hum Genet 81: 252-263.

Rainis L, Bercovich D, Strehl S, Teigler-Schlegel A, Stark B, Trka J et al. (2003). Mutations in exon 2 of GATA1 are early events in megakaryocytic malignancies associated with trisomy 21. Blood 102: 981-986.

Rainis L, Toki T, Pimanda JE, Rosenthal E, Machol K, Strehl S et al. (2005). The proto-oncogene ERG in megakaryoblastic leukemias. Cancer Res 65: 7596-7602.

Russell LJ, Capasso M, Vater I, Akasaka T, Bernard OA, Calasanz MJ et al. (2009). Deregulated expression of cytokine receptor gene, CRLF2, is involved in lymphoid transformation in B-cell precursor acute lymphoblastic leukemia. Blood 114: 2688-2698.

Sakai E, Kitajima K, Sato A, Nakano T. (2009). Increase of hematopoietic progenitor and suppression of endothelial gene expression by Runx1 expression during in vitro ES differentiation. Exp Hematol 37: 334-345.

Salek-Ardakani S, Smooha G, de Boer J, Sebire NJ, Morrow M, Rainis L et al. (2009). ERG is a megakaryocytic oncogene. Cancer Res 69: 4665-4673.

Satge D, Sasco AJ, Carlsen NL, Stiller CA, Rubie H, Hero B et al. (1998). A lack of neuroblastoma in Down syndrome: a study from 11 European countries. Cancer Res 58: 448-452.

Shalaby F, Ho J, Stanford WL, Fischer KD, Schuh AC, Schwartz L et al. (1997). A requirement for Flk1 in primitive and definitive hematopoiesis and vasculogenesis. Cell 89: 981-990.

Shen JJ, Williams BJ, Zipursky A, Doyle J, Sherman SL, Jacobs PA et al. (1995). Cytogenetic and molecular studies of Down syndrome individuals with leukemia. Am J Hum Genet 56: 915-925.

Stankiewicz MJ, Crispino JD. (2009). ETS2 and ERG promote megakaryopoiesis and synergize with alterations in

GATA-1 to immortalize hematopoietic progenitor cells. Blood 113: $3337-3347$.

Sussan TE, Yang A, Li F, Ostrowski MC, Reeves RH. (2008). Trisomy represses Apc(Min)-mediated tumours in mouse models of Down's syndrome. Nature 451: 73-75.

Taub JW, Ravindranath Y. (2002). Down syndrome and the transient myeloproliferative disorder: why is it transient? $J$ Pediatr Hematol Oncol 24: 6-8.

Teyssier-Le Discorde M, Prost S, Nandrot E, Kirszenbaum M. (1999). Spatial and temporal mapping of c-kit and its ligand, stem cell factor expression during human embryonic haemopoiesis. $\mathrm{Br} J$ Haematol 107: 247-253

Toki T, Kanezaki R, Adachi S, Fujino H, Xu G, Sato T et al. (2009). The key role of stem cell factor/KIT signaling in the proliferation of blast cells from Down syndrome-related leukemia. Leukemia 23: 95-103.

Toki T, Katsuoka F, Kanezaki R, Xu G, Kurotaki H, Sun J et al. (2005). Transgenic expression of BACH1 transcription factor results in megakaryocytic impairment. Blood 105: 3100-3108.

Tunstall-Pedoe O, Roy A, Karadimitris A, de la Fuente J, Fisk NM, Bennett $\mathrm{P}$ et al. (2008). Abnormalities in the myeloid progenitor compartment in Down syndrome fetal liver precede acquisition of GATA1 mutations. Blood 112: 4507-4511.

Wang Y, Mulligan C, Denyer G, Delom F, Dagna-Bricarelli F, Tybulewicz VL et al. (2009). Quantitative proteomics characterization of a mouse embryonic stem cell model of Down syndrome. Mol Cell Proteomics 8: 585-595.

Wechsler J, Greene M, McDevitt MA, Anastasi J, Karp JE, Le Beau MM et al. (2002). Acquired mutations in GATA1 in the megakaryoblastic leukemia of Down syndrome. Nat Genet 32: $148-152$.

Yanagida M, Osato M, Yamashita N, Liqun H, Jacob B, Wu F et al. (2005). Increased dosage of Runx1/AML1 acts as a positive modulator of myeloid leukemogenesis in $\mathrm{BXH} 2$ mice. Oncogene 24: 4477-4485.

Yang Q, Rasmussen SA, Friedman JM. (2002). Mortality associated with Down's syndrome in the USA from 1983 to 1997: a population-based study. Lancet 359: 1019-1025.

Zipursky A, Thorner P, De Harven E, Christensen H, Doyle J. (1994). Myelodysplasia and acute megakaryoblastic leukemia in Down's syndrome. Leuk Res 18: 163-171.

Zovein AC, Hofmann JJ, Lynch M, French WJ, Turlo KA, Yang Y et al. (2008). Fate tracing reveals the endothelial origin of hematopoietic stem cells. Cell Stem Cell 3: 625-636.

(c)

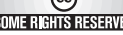

This work is licensed under the Creative Commons Attribution-NonCommercial-No Derivative

Works 3.0 Unported License. To view a copy of this license, visit http://creativecommons.org/licenses/by-nc-nd/3.0/

Supplementary Information accompanies the paper on the Oncogene website (http://www.nature.com/onc) 